Cite this: Soft Matter, 2013, 9, 3915

Received 30th November 2012

Accepted 26th February 2013

DOI: $10.1039 / c 3 s m 27758 \mathrm{e}$

\section{Tuning the amino acid sequence of minimalist peptides to present biological signals via charge neutralised self assembly $\dagger$}

\author{
Alexandra L. Rodriguez, ${ }^{a}$ Clare L. Parish, ${ }^{b}$ David R. Nisbet ${ }^{a}$ and Richard J. Williams ${ }^{c}$
}

www.rsc.org/softmatter

\begin{abstract}
Nanofibrous materials yielded by the self-assembly of peptides are rich in potential; particularly for the formation of scaffolds that mimic the landscape of the host environment of the cell. Here, we report a novel methodology to direct the formation of supramolecular structures presenting desirable amino acid sequences by the selfassembly of minimalist peptides which cannot otherwise yield the desired scaffold structures under biologically relevant conditions. Through the rational modification of the $\mathrm{p} K_{\mathrm{a}}$, we were able to optimise ordered charge neutralised assembly towards in vivo conditions.
\end{abstract}

\section{Introduction}

Three-dimensional (3D) scaffolds that mimic the biomechanical, topographical and biochemical properties of the extracellular matrix (ECM) have attracted considerable interest for their potential use in providing support to cells both in vitro and in vivo. ${ }^{1}$ Scaffolds based upon a nanofibrous matrix formed by the self-assembly of peptides have emerged as promising materials for regenerative medicine as part of a new methodology in scaffold design where a "bottom-up" approach is used in order to mimic the cellular niche., ${ }^{2,3}$ Such materials are suitable for many clinical applications, where scaffolds could be used for endogenous regeneration post disease or tissue insult, or as scaffolds to support cell transplantation. ${ }^{4}$ The capacity to influence cell processes may also provide a further opportunity to tailor a biomaterial to given cellular needs.

${ }^{a}$ Research School of Engineering, College of Engineering and Computer Science, The Australian National University, Acton, ACT 0200, Australia

${ }^{b}$ Florey Neuroscience Institutes, The University of Melbourne, Parkville, VIC 3010, Australia

${ }^{c}$ Centre for Chemistry and Biotechnology (CCB), School of Life and Environmental Sciences, Deakin University, Waurn Ponds, VIC 3217, Australia.E-mail: r.williams@ deakin.edu.au

† Electronic supplementary information (ESI) available: Full experimental materials. See DOI: 10.1039/c3sm27758e
Recently, research has been focused on simulating the native cellular milieu facilitating the observation of cellular processes in vitro and providing a deeper understanding of how cells will respond to physical and biological cues in vivo., ${ }^{\mathbf{1 , 5}}$ The ECM consists of a variety of tissue specific proteins that provide not only physical but also chemical support to cells through initiation of cell pathways via integrin activation. Unique peptide sequences found in these proteins are known to have varying influences on intracellular processes such as adhesion, proliferation, differentiation and migration. ${ }^{6}$ The inclusion of these peptide signals at a high density on large, multicomponent molecules has been shown to direct intracellular signaling and ultimately determine cell fate. ${ }^{7}$ However, from a design and synthetic point of view it is desirable to employ simple building blocks which retain the capacity to fabricate complex, information-rich, supramolecular assemblies. ${ }^{8}$ The use of selfassembling peptides (SAPs) as building blocks to fabricate biomaterials is advantageous due to their inherent biocompatibility, low cost and ease of synthesis. ${ }^{9}$ In addition, as the structural motif is a peptide sequence, the supramolecular matrices formed by SAPs are bioactive through the presentation of biochemical and biomechanical signals in a context similar to the natural ECM, making them ideal for providing structural and chemical support in a cellular context. ${ }^{\mathbf{1 0}}$

Previous studies have identified a mechanism whereby minimalist peptide derivatives form supramolecular structures through a self-assembly process known as $\pi$ - $\beta$ assembly. ${ }^{\mathbf{1 1}}$ Here, fluorenylmethoxycarbonyl (Fmoc) based SAPs consist of a peptide sequence protected at the amino $(\mathrm{N})$ terminus by an aromatic Fmoc moiety. The individual Fmoc-peptides interact non-covalently to induce the formation of highly ordered $3 \mathrm{D}$ fibrillar networks based on thermodynamic stabilisation. ${ }^{12}$ The aromatic groups in the Fmoc share electrons to form $\pi-\pi$ interactions creating the backbone of the nanofibrous structures. The peptides interact with each other via hydrogen bonds to form secondary protein structures such as $\beta$-sheets. Through the coalescence of several of these assemblies individual fibres are formed, nanometers in diameter and microns in length. ${ }^{13}$ 
Bundles of these nanofibres go on to form supramolecular associations leading to the formation of a complete, highly branched nanofibrous network which presents as a macroscale hydrogel. ${ }^{14}$ Importantly, by using this method, the amino acid side chains of the peptide moieties are presented on the outer edge of the nanofibres to create a surface rich in bioactive molecules. ${ }^{11,15}$

Thus far, $\pi-\beta$ assemblies have been restricted to tripeptide signals with the inherent capacity to assemble at physiological $\mathrm{pH}$. This has been demonstrated through the development of SAPs incorporating the fibronectin-based sequence, arginineglycine-aspartate (RGD), a sequence known to promote cell adhesion. ${ }^{16}$ The amino acid sequences are chosen for their bioactivity and yet must contribute to the structural component, potentially under non-ideal conditions in terms of propensity to assemble, solubility, and charge. For cell culture and potential in vivo applications, SAPs must be designed to undergo optimal self-assembly under mild, physiological conditions $\left(37^{\circ} \mathrm{C}, \mathrm{pH}\right.$ 7.4, high ionic strength etc.) and ideally without the use of strong organic solvents (such as 1,1,1,3,3,3-hexafluoro-2-propanol ${ }^{17}$ ) which could potentially leave an undesirable residue.

In order to make a hydrogel from these building blocks, free from any traces of organic solvents, a pH switch was applied. ${ }^{18}$ At high pH, the peptides are solubilised to a clear solution. Eventually, with the dropwise addition of acid, a $\mathrm{pH}$ is reached where the attractive forces of the peptide outweigh the repulsive forces provided by the charged groups, and the peptide building blocks undergo a spontaneous transition from unordered, solvated peptides to organised self-assembled structures as shown diagrammatically in Scheme 1.

The Fmoc-protected peptide contains ionisable groups, both on the amino acid side chains and the peptide backbone. They therefore present a sequence specific $\mathrm{p} K_{\mathrm{a}}$ and yet are observed to self-assemble at a $\mathrm{pH}$ several units higher than these values. ${ }^{19}$ These shifts in $\mathrm{p} K_{\mathrm{a}}$ have been shown to take place between the calculated $\mathrm{p} K_{\mathrm{a}}$ of a dipeptide $(\sim 3.5)$, and the observed $\mathrm{p} K_{\mathrm{a}}$ of $\sim 6$ upon its assembly. It has been suggested that this phenomenon is a result of screening of the ionisable groups upon assembly, and the non-zwitterionic nature of the N-terminally capped
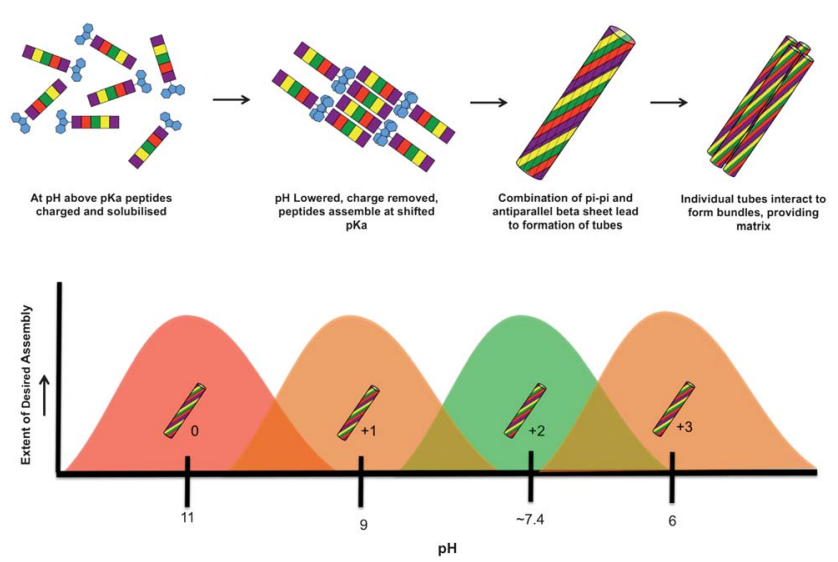

Scheme 1 Schematic of assembly process (top); diagram to show the adjustment of the range of self-assembly to optimal conditions with sequential addition of acidic residue (bottom).
Fmoc-peptides. The sequence of amino acids strongly determines the $\mathrm{p} K_{\mathrm{a}}$ of the peptide and therefore the $\mathrm{pH}$ at which selfassembly occurs. Previous studies have shown that the addition of charged lysine residues can alter the conditions under which $\beta$-hairpin assembly occurs. ${ }^{20}$ We therefore hypothesised that we could fabricate scaffolds from peptide sequences, that would otherwise not assemble at biological conditions, by modifying the extent of this $\mathrm{p} K_{\mathrm{a}}$ shift through a general approach, where inclusion of any charged residue would tune the $\mathrm{pH}$ under which ordered assembly occurs. This process would then allow us to 'tune' the assembly process to biologically relevant conditions by optimising the non-covalent interactions (both ionic and hydrophobic) that drive the assembly (Scheme 1). The pentameric laminin peptide sequence isoleucine-lysine-valine-alanine-valine (IKVAV) was selected as a suitable target. Laminin is a key proteinaceous component of the ECM. The effective presentation of this peptide has been identified as a key signal for promoting neural adhesion, migration, proliferation and differentiation. ${ }^{21}$ We synthesised a small library of IKVAV containing peptides (Scheme 2), which varied in terms of their $\mathrm{p} K_{\mathrm{a}}$ via the inclusion of aspartic acid (D) residues to the N-terminus of the SAP. This process is not considered to increase the hydrophobicity of the peptide, especially at a $\mathrm{pH}$ higher than the $\mathrm{p} K_{\mathrm{a}}$ of the carboxyl group. Four IKVAV-including sequences were synthesised with the goal of forming a clear, self-supporting hydrogel at $\mathrm{pH}$ 7.4: Fmoc-IKVAV ( $\mathrm{p} K_{\mathrm{a}}$ of 6.42), Fmoc-DIKVAV (p $K_{\mathrm{a}}$ of 3.1), FmocDDIKVAV ( $\mathrm{p} K_{\mathrm{a}}$ of 2.92) and Fmoc-DDDIKVAV ( $\mathrm{p} K_{\mathrm{a}}$ of 2.82). In order to investigate any shift in $\mathrm{p} K_{\mathrm{a}}$ resulting from the addition of

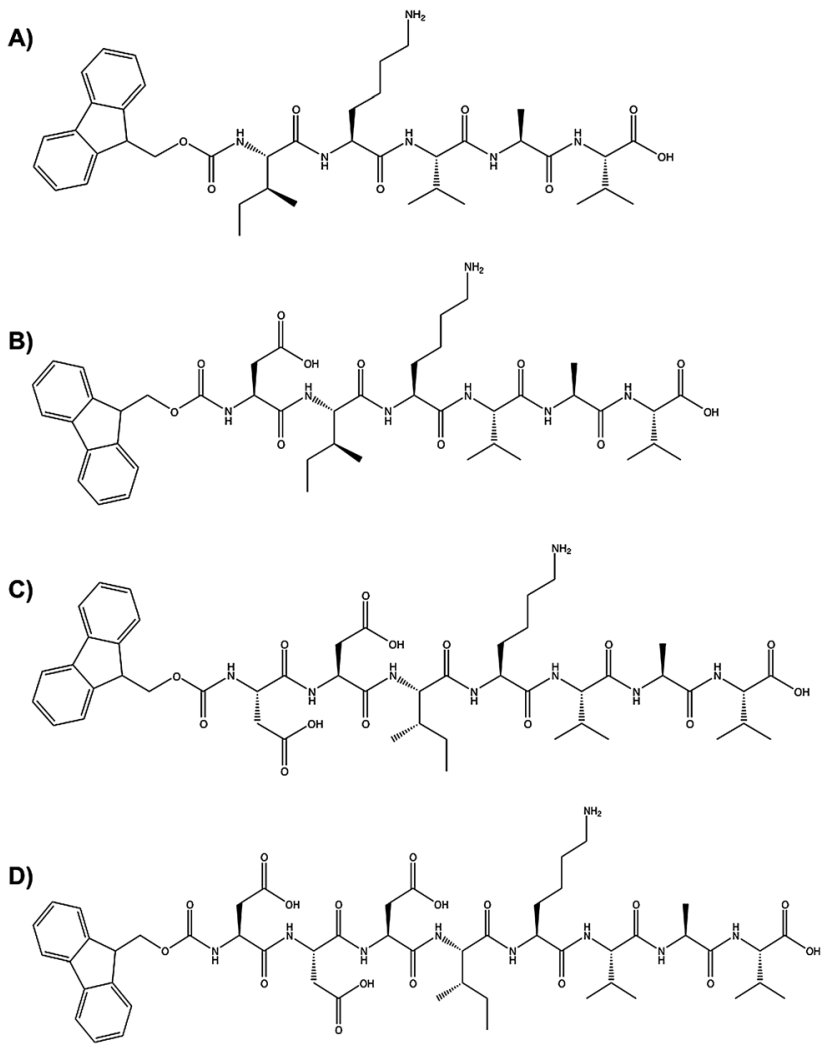

Scheme 2 Structures of the IKVAV containing peptides. (A) Fmoc-IKVAV, (B) Fmoc-DIKVAV, (C) Fmoc-DDIKVAV, and (D) Fmoc-DDDIKVAV. 

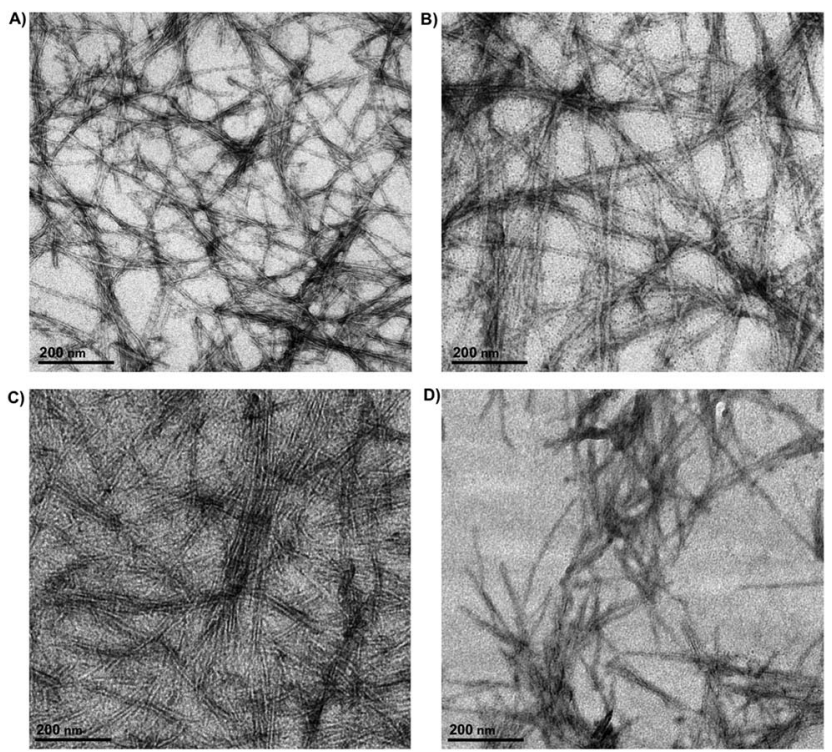

Fig. 1 TEM images of nanoscale structures underpinning the formation of the peptide hydrogels under optimal conditions for each peptide: (A-D) Fmoc-IKVAV (pH 11), -DIKVAV (pH 9), -DDIKVAV (pH 7.4), and -DDDIKVAV (pH 6) respectively.

a $D$ residue(s), a titration experiment was carried out on the four IKVAV-containing peptides (Fig. 1A). Two $\mathrm{p} K_{\mathrm{a}}$ shifts were observed for the unmodified sequence of Fmoc-IKVAV at $\mathrm{pH}$ approximately 12.5 and 10 (Fig. 2A). This corresponds to the $\mathrm{pH}$ at which the peptide was observed to undergo solution-gelation transition, with a hydrogel formed at $\mathrm{pH} \sim 11.5$, conditions unsuitable for cell culture. When the $\mathrm{pH}$ was lowered further, a disordered aggregate/precipitate formed.

Fmoc-DIKVAV followed similar transitions, but at a lower $\mathrm{pH}$ ( 9). It also collapsed to a disordered aggregate below this $\mathrm{pH}$ (see ESI $\dagger$ ). The addition of a second acidic residue to Fmoc-DDIKVAV, resulted in a significantly reduced transition, and importantly, yielded a rigid hydrogel at $\mathrm{pH} \sim 7.4$. Fmoc-DDDIKVAV formed a hydrogel at $\mathrm{pH}$ 6, maintaining the trend. Importantly, due to the use of the acid/base switch, this process occurred in an ionic environment comparable to physiological conditions. In addition, hydrogels of Fmoc-DDIKVAV proved to be stable when formed in phosphate buffered saline at $\mathrm{pH}$ 7.4. It was not possible to form the typical nanoscale fibrils or a hydrogel from either FmocIKVAV, -DIKVAV or -DDDIKVAV at pH 7.4 using an alternative temperature switch. ${ }^{22}$ This approach resulted in the formation of a disordered precipitate (see ESI $\dagger$ ).

We performed a series of experiments to confirm that all four peptides yielded the desired nanofibrous matrix in addition to the hydrogel. The nanoscale morphologies of the structures underpinning each hydrogel were assessed via transmission electron microscopy (TEM). TEM micrographs demonstrated that the hydrogels arising from each peptide sequence of the library gave a nanostructured fibrous network of comparable morphologies (Fig. 1). Each peptide sequence formed nanofibres of $\sim 10 \mathrm{~nm}$ in diameter with similar structure. This suggested that the non-covalent interactions that allowed the formation of a highly ordered nanofibrous network were robust enough to overcome a change in peptide sequence, length and overall charge. The network observed for Fmoc-DDDIKVAV, however, was observed to be fragmented compared to the shorter sequences, indicating that eight residues may be toward the upper limit for stable $\pi-\beta$ assembly.

To confirm that the library of observed nanostructures were underpinned by $\pi$ - $\beta$ assembly motifs, a number of characterisation studies were performed. Fourier transform infrared spectroscopy (FT-IR) was used to investigate the peptide backbone of the various assemblies (Fig. 2B). Analysis of the amide I region revealed characteristic spectra for this class of material. ${ }^{\mathbf{1 2}}$ A major peak at approximately $1630 \mathrm{~cm}^{-1}$ and a minor peak at $1690 \mathrm{~cm}^{-1}$, as observed in Fig. 2B, represent anti-parallel $\beta$-sheets. A third smaller peak centered on $1660 \mathrm{~cm}^{-1}$ represents the presence of some $\alpha$-helical structures within the $\pi-\beta$ morphology. The FT-IR spectra for the four different peptide

\section{A)}

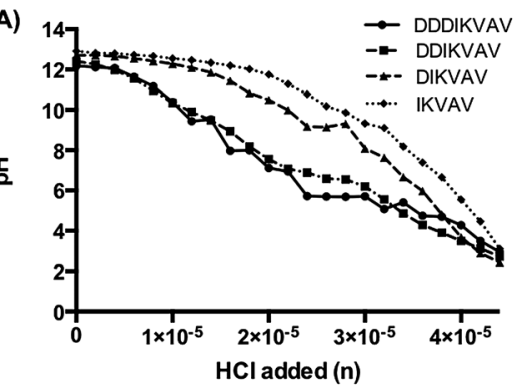

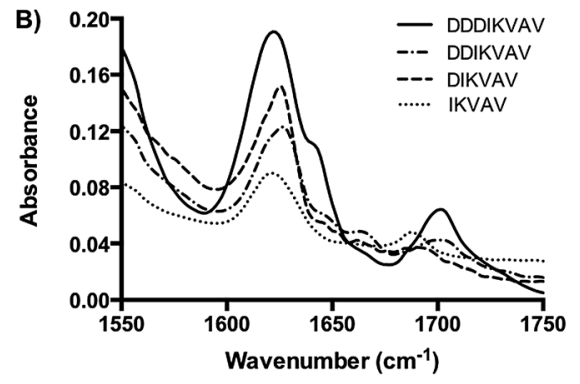
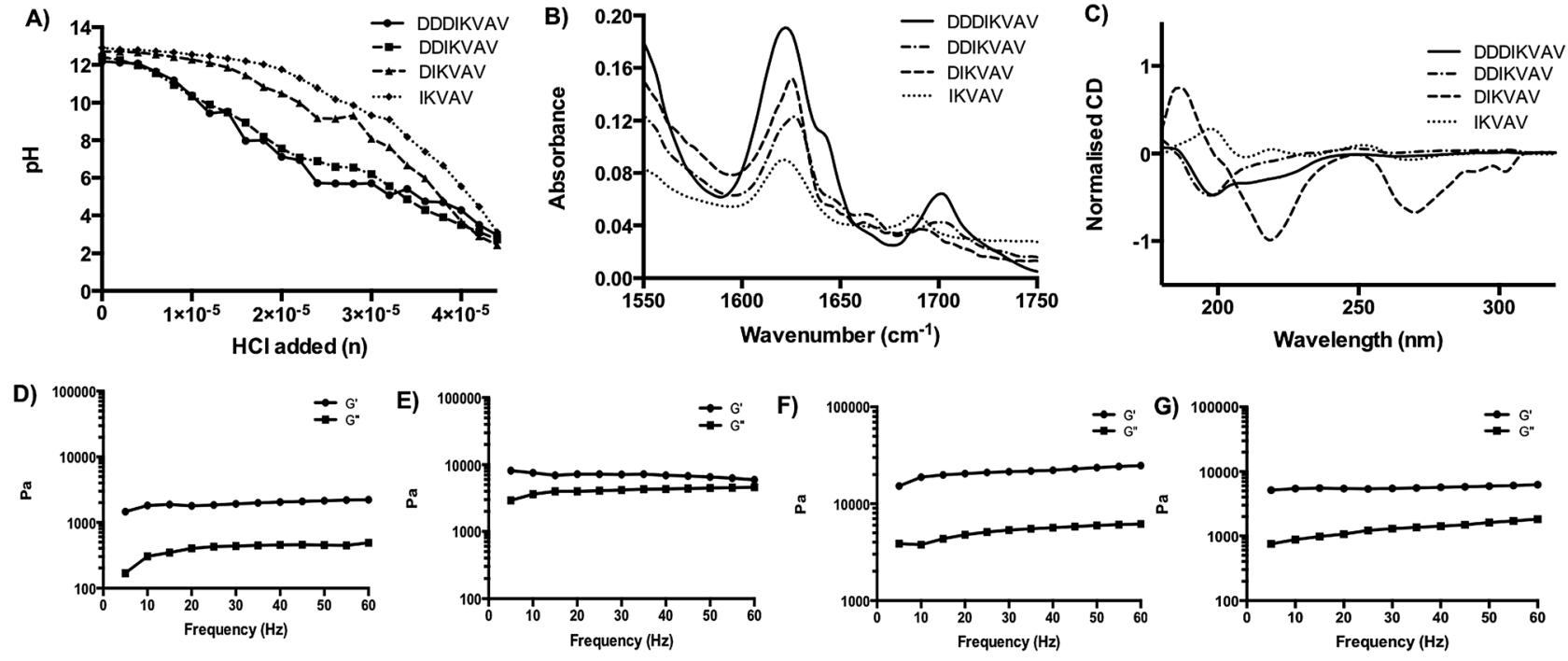

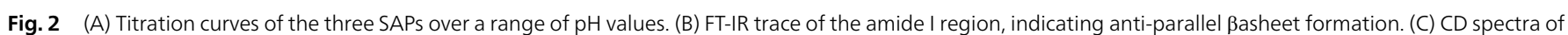
all three assemblies show characteristic transitions. (D-G) $G^{\prime} / G^{\prime \prime}$ traces of Fmoc-IKVAV, -DIKVAV, -DDIKVAV and -DDDIKVAV respectively. 
sequences showed similar peaks, confirming that hydrogen bonding between individual peptide sequences was unaffected by the addition of $\mathrm{D}$ residues.

The ordering of peptide self-assembled fibrils has been shown to give pronounced circular dichroism (CD) signals related to the chiral organisation within and between the fibrils, analogous to large macromolecules. ${ }^{3,23}$ CD spectroscopy revealed a transition in the $230-270 \mathrm{~nm}$ region arising from supramolecular ordering between fibrils due to their lateral alignment (Fig. 2C). The amide regions of the system $(<220 \mathrm{~nm})$ showed transitions indicative of the presence of $\beta$-sheets, reinforcing the FT-IR data. Transitions in the $260-310 \mathrm{~nm}$ region, shown in Fig. 2C, are the result of aromatic Fmoc- $\pi$ stacking, in accordance with other similar assemblies. ${ }^{\mathbf{1 1}}$ Interestingly, Fmoc-DIKVAV resulted in an inversion of the chiral signal in this region as compared to Fmoc-IKVAV. The addition of the second and third D in Fmoc-DDIKVAV and FmocDDDIKVAV reverted this signal, although it was observed that the rest of the spectrum was conserved. This change in orientation did not affect the $\pi$ - $\beta$ assembly or overall supramolecular structure of the nanofibrous network and may be related to ordering differences of the penta-, hexa- and septa- and octameric nature of the SAP library.

Finally, the mechanical properties of the hydrogels were compared with rheological testing of the self-assembled hydrogels (Fig. 2D-G). For all four sequences, characteristic viscoelastic gel behaviour was observed, where the storage modulus $\left(G^{\prime}\right)$ is greater than the loss modulus $\left(G^{\prime \prime}\right)$ with only a slight dependence on increasing frequency. ${ }^{12}$ Importantly, The addition of $\mathrm{D}$ residues appeared to increase the overall stiffness of the gel with Fmoc-DDIKVAV having the highest $G^{\prime}$ ranging from $10-30 \mathrm{kPa}$ over increasing frequency as compared with the Fmoc-IKVAV, and an increase in the $G^{\prime} / G^{\prime \prime}$ ratio over Fmoc-DIKVAV. Fmoc-DDDIKVAV showed similar, if slightly weaker stiffness than the Fmoc-DDIKVAV hydrogel. This compares well with the properties of soft tissue, ${ }^{24}$ whilst also highlights that the mechanical properties of the gel are tuneable for specific tissue types through adjustment of the peptide sequence.

\section{Conclusions}

This study presents a powerful new methodology for the incorporation of bioactive signals within a minimalistic selfassembling scaffold. Through the rational modification of a bioactive peptide sequence with acidic residues, we were able to controllably shift the $\mathrm{p} K_{\mathrm{a}}$ and, as a consequence, shifting the $\mathrm{pH}$ at which charge-neutralised self-assembly of IKVAV containing peptides occurs from $\mathrm{pH} \sim 12$ to 7.4. Importantly, this modification had no effect on the non-covalent interactions between individual SAPs responsible for self-assembly. The resulting Fmoc-DDIKVAV SAP, therefore, yielded a nanofibrous architecture with the capacity to present highly relevant biochemical and biomechanical cues at physiological $\mathrm{pH}$ to cells in vitro and/ or in vivo, a key objective in the design of biomaterials for regenerative medicine.

\section{Acknowledgements}

We wish to thank Dr Antonio Tricoli for critical reading of the manuscript. We would also like to thank Dr Navdeep Kaur and Joanne Lee (Centre for Advanced Microscopy, ANU) for their help and guidance in preparing negative stains for TEM imaging. This research was supported by funding from the National Health and Medicine Research Council (NHMRC, APP1020332 to DRN) and from the Australian Research Council (ARC, DP130103131). ALR was supported by an Australian Postgraduate Award; CLP was supported by an NHMRC Career Development Award, and subsequently Senior Medical Research Fellowship provided by the Viertel charitable Foundation, Australia; DRN was supported by an Australian Research Council Australian Postdoctoral Fellowship, and subsequently by a NHMRC Career Development Fellowship; and RJW was supported by an Alfred Deakin Research Fellowship. The authors wish to thank Peta Nisbet for photography.

\section{Notes and references}

1 J. T. S. Pettikiriarachchi, C. L. Parish, M. S. Shoichet, J. S. Forsythe and D. R. Nisbet, Aust. J. Chem., 2010, 63, 1143.

2 Y. L. Yang, U. Khoe, X. M. Wang, A. Horii, H. Yokoi and S. G. Zhang, Nano Today, 2009, 4, 193.

3 R. J. Williams, T. E. Hall, V. Glattauer, J. White, P. J. Pasic, A. B. Sorensen, L. Waddington, K. M. McLean, P. D. Currie and P. G. Hartley, Biomaterials, 2011, 32, 5304.

4 D. Nisbet and R. Williams, Biointerphases, 2012, 7, 1.

5 T.-Y. Wang, J. S. Forsythe, D. R. Nisbet and C. L. Parish, Biomaterials, 2012, 33, 9188.

6 D. R. Zimmermann and M. T. Dours-Zimmermann, Histochem. Cell Biol., 2008, 130, 635.

7 V. M. Tysseling-Mattiace, V. Sahni, K. L. Niece, D. Birch, C. Czeisler, M. G. Fehlings, S. I. Stupp and J. A. Kessler, J. Neurosci., 2008, 28, 3814; X. Wang, A. Horii and S. Zhang, Soft Matter, 2008, 4, 2388.

8 M. Zelzer and R. V. Ulijn, Chem. Soc. Rev., 2010, 39, 3351.

9 R. V. Ulijn and A. M. Smith, Chem. Soc. Rev., 2008, 37, 664. 10 J. B. Matson and S. I. Stupp, Chem. Commun., 2012, 48, 26.

11 A. M. Smith, R. J. Williams, C. Tang, P. Coppo, R. F. Collins, M. L. Turner, A. Saiani and R. V. Ulijn, Adv. Mater., 2008, 20, 37.

12 R. J. Williams, A. M. Smith, R. Collins, N. Hodson, A. K. Das and R. V. Ulijn, Nat. Nanotechnol., 2009, 4, 19.

13 S. Toledano, R. J. Williams, V. Jayawarna and R. V. Ulijn, J. Am. Chem. Soc., 2006, 128, 1070.

14 R. J. Williams, R. J. Mart and R. V. Ulijn, Pept. Sci., 2010, 94, 107.

15 H. Xu, A. K. Das, M. Horie, M. S. Shaik, A. M. Smith, Y. Luo, X. Lu, R. Collins, S. Y. Liem, A. Song, P. L. A. Popelier, M. L. Turner, P. Xiao, I. A. Kinloch and R. V. Ulijn, Nanoscale, 2010, 2, 960.

16 G. Cheng, V. Castelletto, R. R. Jones, C. J. Connon and I. W. Hamley, Soft Matter, 2011, 7, 1326; M. Zhou, A. M. Smith, A. K. Das, N. W. Hodson, R. F. Collins, R. V. Ulijn and J. E. Gough, Biomaterials, 2009, 30, 2523; 
R. Orbach, L. Adler-Abramovich, S. Zigerson, I. MironiHarpaz, D. Seliktar and E. Gazit, Biomacromolecules, 2009, 10, 2646.

17 M. Reches and E. Gazit, FEBS J., 2005, 272, 388.

18 V. Jayawarna, A. Smith, J. E. Gough and R. V. Ulijn, Biochem. Soc. Trans., 2007, 35, 535.

19 C. Tang, A. M. Smith, R. F. Collins, R. V. Ulijn and A. Saiani, Langmuir, 2009, 25, 9447.

20 K. Rajagopal, M. S. Lamm, L. A. Haines-Butterick, D. J. Pochan and J. P. Schneider, Biomacromolecules, 2009, 10, 2619.
21 J. B. Matson, R. Helen Zha and S. I. Stupp, Curr. Opin. Solid State Mater. Sci., 2011; V. Tysseling, V. Sahni, E. Pashuck, D. Birch, A. Hebert, C. Czeisler, S. Stupp and J. Kessler, J. Neurosci. Res., 2010, 88, 3161.

22 Z. M. Yang, H. W. Gu, Y. Zhang, L. Wang and B. Xu, Chem. Commun., 2004, 208.

23 A. R. Hirst, S. Roy, M. Arora, A. K. Das, N. Hodson, P. Murray, S. Marshall, N. Javid, J. Sefcik, J. Boekhoven, J. H. van Esch, S. Santabarbara, N. T. Hunt and R. V. Ulijn, Nat. Chem., 2010, 2, 1089.

24 Z. Taylor and K. Miller, J. Biomech., 2004, 37, 1263. 